University of Nebraska - Lincoln

DigitalCommons@University of Nebraska - Lincoln

\title{
Effects of Short Exposures to Spinosad-Treated Wheat or Maize on Four Stored-Grain Insects
}

Christos G. Athanassiou

Agricultural University of Athens, athanas@aua.gr

Frank H. Arthur

USDA-ARS, frank.arthur@ars.usda.gov

James E. Throne

USDA-ARS, Manhattan, KS, james.throne@ars.usda.gov

Follow this and additional works at: https://digitalcommons.unl.edu/usdaarsfacpub

Athanassiou, Christos G.; Arthur, Frank H.; and Throne, James E., "Effects of Short Exposures to SpinosadTreated Wheat or Maize on Four Stored-Grain Insects" (2010). Publications from USDA-ARS / UNL Faculty. 2034.

https://digitalcommons.unl.edu/usdaarsfacpub/2034

This Article is brought to you for free and open access by the U.S. Department of Agriculture: Agricultural Research Service, Lincoln, Nebraska at DigitalCommons@University of Nebraska - Lincoln. It has been accepted for inclusion in Publications from USDA-ARS / UNL Faculty by an authorized administrator of DigitalCommons@University of Nebraska - Lincoln. 


\title{
Effects of Short Exposures to Spinosad-Treated Wheat or Maize on Four Stored-Grain Insects
}

\author{
CHRISTOS G. ATHANASSIOU, ${ }^{1,2,3}$ FRANK H. ARTHUR, ${ }^{2}$ and JAMES E. THRONE ${ }^{2}$
}

J. Econ. Entomol. 103(1): 197-202 (2010); DOI: 10.1603/EC09115

\begin{abstract}
The effect of short exposures to spinosad-treated wheat, Triticum aestivum L., or maize, Zea mays L., was evaluated against adults of four stored-product insect species: lesser grain borer, Rhyzopertha dominica (F.) (Coleoptera: Bostrichidae); rice weevil, Sitophilus oryzae (L.) (Coleoptera: Curculionidae); red flour beetle, Tribolium castaneum (Herbst) (Coleoptera: Tenebrionidae); and the psocid Lepinotus reticulatus (Enderlein) (Psocoptera: Trogiidae). Adult mortality of these species was recorded after 0,2 , $4,8,16$, and $40 \mathrm{~h}$ on commodities treated with $1 \mathrm{ppm}$ of spinosad (immediate mortality). Then, the surviving individuals were removed and placed on untreated wheat or maize, and mortality was recorded again $7 \mathrm{~d}$ later (delayed mortality). Progeny production then was determined 65 and $35 \mathrm{~d}$ later for the beetles and psocids, respectively. Among the four species tested, $R$. dominica was the most susceptible, and immediate mortality after $40 \mathrm{~h}$ reached 78 and $72 \%$ on wheat and maize, respectively. Moreover, $7 \mathrm{~d}$ later, all adults that had been exposed for $>2 \mathrm{~h}$ were dead on both commodities. Progeny production was significantly reduced in comparison with the controls, and no progeny were found when parental adults had been exposed for $>8$ or $>4$ h on wheat and maize, respectively. For $S$. oryzae, 40-h exposures significantly increased delayed mortality on both wheat and maize, but progeny production still was high. Generally, no effect of short exposures was noted for T. castaneum. For L. reticulatus, despite the fact that the increase of exposure interval increased mortality on maize, progeny production was not avoided. With the exception of T. castaneum, more progeny were found on wheat than on maize. The results of the current study indicate that $R$. dominica is very susceptible after short exposures to spinosad-treated substrate, but the other species are able to survive and reproduce at the exposure range examined.
\end{abstract}

KEY WORDS Rhyzopertha dominica, Sitophilus oryzae, Tribolium castaneum, Lepinotus reticulatus, stored products

Spinosad is a bacterium-derived broad-spectrum insecticide which has received U.S. Environmental Protection Agency approval for its use as a grain protectant in 2005, at the application rate of $1 \mathrm{mg} / \mathrm{kg}$ grain (Subramanyam 2006). Before this, spinosad has already been proved very effective against a range of stored-grain insect species, even at lower rates than the application rate, in both laboratory (Fang et al. 2002a, Toews and Subramanyam 2003, Nayak et al. 2005, Daglish and Nayak 2006) and field tests (Maier et al. 2006, Subramanyam et al. 2007, Daglish et al. 2008). Due to the above-mentioned characteristics and its low mammalian toxicity, spinosad is a desirable alternative to the use of traditional grain protectants, especially organophosphorous insecticides (OPs), which often are very toxic to mammals. In addition,

Mention of trade names or commercial products in this publication is solely for the purpose of providing specific information and does not imply recommendation or endorsement by the United Stated Department of Agriculture or the Agricultural University of Athens.

${ }^{1}$ Laboratory of Agricultural Zoology and Entomology, Agricultural University of Athens, 75 Iera Odos, 11855 Athens, Greece.

2 Corresponding author, e-mail: athanas@aua.gr.

${ }^{3}$ USDA-ARS, Grain Marketing and Production Research Center, 1515 College Ave., Manhattan KS 66502-2736. many studies indicate that spinosad often is even more effective than OPs against many stored-grain insect species. For example, in a field study, Subramanyam et al. (2007) noted that spinosad was more effective than chlorpyriphos-methyl against the lesser grain borer, Rhyzopertha dominica (F.) (Coleoptera: Bostrichidae) on wheat, Triticum aestivum $\mathrm{L}$. In addition, in a laboratory experiment, Huang and Subramanyam (2004) reported that spinosad was superior to pirimiphos-methyl against the rice moth, Corcyra cephalonica (Stainton) (Lepidoptera: Pyralidae).

An ideal grain protectant should combine rapid mortality with long-term stability (Arthur 1996). In storage facilities, in the absence of light, spinosad remains stable for a long period; thus, it can provide long-term protection for stored grains (Fang et al. 2002b, Fang and Subramanyam 2003). In bulk grains, however, uneven distribution of the insecticide is likely to occur, which may result in the existence of areas that are only partially treated or practically untreated, and can act as refugia for future infestations. Hence, if rapid mortality does not occur, the exposed insects may migrate to untreated layers, lay eggs before death, and continue to cause grain damage. For example, another category of grain protectants, the 
Table 1. Repeated-measures ANOVA parameters for immediate and delayed mortality of the species tested $($ error df $=48)$

\begin{tabular}{|c|c|c|c|c|c|c|c|c|c|}
\hline \multirow{2}{*}{ Source } & \multirow{2}{*}{ df } & \multicolumn{2}{|c|}{ R. dominica } & \multicolumn{2}{|c|}{ S. oryzae } & \multicolumn{2}{|c|}{ T. castaneum } & \multicolumn{2}{|c|}{ L. reticulatus } \\
\hline & & $F$ & $P$ & $F$ & $P$ & $F$ & $P$ & $F$ & $P$ \\
\hline Between variables & 11 & 48.9 & $<0.01$ & 32.6 & $<0.01$ & 4.01 & $<0.01$ & 5.8 & $<0.01$ \\
\hline Intercept & 1 & 179.9 & $<0.01$ & 225.0 & $<0.01$ & 36.2 & $<0.01$ & 459.5 & $<0.01$ \\
\hline Immediate mortality & 5 & 49.9 & $<0.01$ & 73.1 & $<0.01$ & 4.5 & $<0.01$ & 7.3 & $<0.01$ \\
\hline Commodity & 1 & 0.01 & 0.49 & 16.5 & $<0.01$ & 7.3 & $<0.01$ & 20.8 & $<0.01$ \\
\hline Immediate $\times$ commodity & 5 & 0.1 & 0.62 & 2.1 & 0.09 & 2.9 & 0.02 & 1.3 & 0.27 \\
\hline Within variables & 11 & 100.3 & $<0.01$ & 4.8 & $<0.01$ & 1.1 & 0.42 & 1.2 & 0.32 \\
\hline Delayed & 1 & 3237.9 & $<0.01$ & 20.7 & $<0.01$ & 3.5 & 0.07 & 84.1 & $<0.01$ \\
\hline Delayed $\times$ Immediate & 5 & 219.9 & $<0.01$ & 8.4 & $<0.01$ & 0.84 & 0.53 & 2.2 & 0.07 \\
\hline Delayed $\times$ commodity & 1 & 2.4 & 0.12 & 0.85 & 0.36 & 1.8 & 0.19 & 0.1 & 0.74 \\
\hline All three & 5 & 0.2 & 0.95 & 2.0 & 0.10 & 1.1 & 0.37 & 0.4 & 0.84 \\
\hline
\end{tabular}

diatomaceous earths (DEs), are generally slow-acting, and progeny development is likely even in cases of complete parental mortality (Athanassiou et al. 2003, 2004a). Vardeman et al. (2007) found that R. dominica adults were able to penetrate a DE-treated surface layer of wheat and oviposit in the untreated layer below, whereas temperature and exposure interval had no effect on adult survival or progeny production. Spinosad is considered as a slow-acting insecticide compared with OPs or pyrethroids. Athanassiou et al. (2008a) found that even when there is high parental mortality of adults of the rice weevil, Sitophilus oryzae (L.) (Coleoptera: Curculionidae), progeny production in spinosad-treated wheat, barley, Hordeum vulgare L., or maize, Zea mays L., was not totally avoided. This characteristic is particularly important in the case of primary colonizers, such as $R$. dominica or S. oryzae, where immature development occurs within grain kernels; thus, larvae remain "invulnerable" to the influence of the contact insecticide that is present in the external part of the kernel (Arthur and Throne 2003). Arthur (1992) noted that survival of maize weevils, Sitophilus zeamais Motschulsky (Coleoptera: Curculionidae), and red flour beetles, Tribolium castaneum (Herbst) (Coleoptera: Tenebrionidae), occurred on mixtures of chlorpyriphos-methyl-treated and untreated corn, whereas mixture treatments were much more effective than surface treatments. Moreover, Arthur (1998a,b) found that T. castaneum adults were able to survive after short exposures on concrete treated with cyfluthrin, whereas the presence of food increased survival. However, there are no published data on the influence of short exposures of insects to spinosad-treated grain.

The purpose of our study was to determine whether short exposures of insects to spinosad-treated wheat or maize affect mortality of four stored-grain insect pests, two primary colonizers, R. dominica and S. oryzae, and two secondary colonizers, T. castaneum and the psocid Lepinotus reticulatus Enderlein (Psocoptera: Trogiidae). In addition to mortality, the progeny production of the exposed individuals after transfer to untreated grains also was evaluated.

\section{Materials and Methods}

Insects. Only adults were used in the tests. L. reticulatus is a thelytokous parthenogenetic species
(Mockford 1993); thus, all adults used were females. The beetle species were reared at $27.5^{\circ} \mathrm{C}, 75 \% \mathrm{RH}$, and continuous darkness on whole wheat for $R$. dominica and $S$. oryzae, or on wheat flour plus brewer's yeast ( $5 \%$ by weight), for T. castaneum. L. reticulatus was reared at $30^{\circ} \mathrm{C}, 75 \% \mathrm{RH}$, and continuous darkness on a mixture of $97 \%$ cracked wheat, $2 \%$ rice crispies, and $1 \%$ brewer's yeast (Opit and Throne 2008). The adults used in the bioassays were $<3$ wk old.

Commodity and Insecticide Treatment. Untreated whole wheat (a mixture of variety Fuller and variety Santa Fe) and maize (hybrid Asgrow RX899) adjusted to $13.5 \%$ moisture content by addition of water were used for the tests. The insecticide formulation was spinosad NAF 313 (13\% active ingredient [AI], obtained from Dow AgroSciences, Indianapolis, IN). Lots of grain of $0.5 \mathrm{~kg}$ each were sprayed with spinosad at the label rate of one ppm by using a Badger 100 artists' airbrush (Badger Air-Brush Company, Franklin Park, IL). Additional 0.5-kg lots were sprayed with water and used as controls.

Bioassays. The bioassays were carried out in five replicates. From each lot of wheat or maize, samples of $20 \mathrm{~g}$ each were taken, and each sample was placed in a plastic cylindrical vial $(3 \mathrm{~cm}$ in diameter, $8 \mathrm{~cm}$ in height). Twenty adults of an individual species were placed in a vial, and all vials were placed in incubators set at $27.5^{\circ} \mathrm{C}, 75 \% \mathrm{RH}$, and continuous darkness. The adults were exposed for $0,2,4,8,16$, and $40 \mathrm{~h}$ to the spinosad-treated or untreated grains. After this interval, the mortality of the adults was determined, and the surviving adults were transferred to new vials containing untreated grain and kept at the same conditions for $7 \mathrm{~d}$. In the case of T. castaneum and L. reticulatus, the untreated commodities contained 5\% cracked kernels, given that these species are secondary colonizers and cannot develop easily on sound grains. Then, the number of dead adults was counted, all adults (dead and alive) were removed, and the vials were returned to the same conditions. Thirty-five days later for L. reticulatus and $65 \mathrm{~d}$ later for the other species, the vials were examined for progeny. For $R$. dominica and S. oryzae, the immature development occurs in the interior part of the kernel, so only adult progeny were recorded. For T. castaneum, which is an external feeder, the numbers of adults, pupae and larvae were recorded separately. Similarly, for L. re- 
Table 2. Mean immediate and delayed mortality $(\% \pm \mathrm{SE})$ for the species tested after exposure for $0,2,4,8,16$, and $40 \mathrm{~h}$ in spinosad-treated wheat (within each column, means followed by the same letter are not significantly different; where no letters exist, no significant differences were noted; HSD test at 0.05)

\begin{tabular}{|c|c|c|c|c|c|c|c|c|}
\hline \multirow{3}{*}{ Exposure $(\mathrm{h})$} & \multicolumn{8}{|c|}{ Species/mortality } \\
\hline & \multicolumn{2}{|c|}{ R. dominica } & \multicolumn{2}{|c|}{ S. oryzae } & \multicolumn{2}{|c|}{ T. castaneum } & \multicolumn{2}{|c|}{ L. reticulatus } \\
\hline & Immediate & Delayed & Immediate & Delayed & Immediate & Delayed & Immediate & Delayed \\
\hline 0 & $0.0 \pm 0.0 \mathrm{a}$ & $1.6 \pm 1.0 \mathrm{a}$ & $0.0 \pm 0.0 \mathrm{a}$ & $2.0 \pm 2.0 \mathrm{a}$ & $0.0 \pm 0.0$ & $0.0 \pm 0.0$ & $0.0 \pm 0.0$ & $15.4 \pm 5.7$ \\
\hline 2 & $1.5 \pm 1.0 \mathrm{a}$ & $86.7 \pm 6.1 b$ & $0.0 \pm 0.0 \mathrm{a}$ & $5.5 \pm 2.9 \mathrm{a}$ & $0.0 \pm 0.0$ & $0.0 \pm 0.0$ & $9.1 \pm 5.2$ & $33.1 \pm 4.5$ \\
\hline 4 & $5.4 \pm 2.8 \mathrm{a}$ & $100.0 \pm 0.0 \mathrm{c}$ & $0.0 \pm 0.0 \mathrm{a}$ & $5.0 \pm 2.6 \mathrm{a}$ & $0.0 \pm 0.0$ & $2.5 \pm 1.9$ & $7.4 \pm 3.8$ & $26.5 \pm 4.4$ \\
\hline 8 & $4.0 \pm 2.1 \mathrm{a}$ & $100.0 \pm 0.0 \mathrm{c}$ & $1.0 \pm 0.6 \mathrm{a}$ & $2.1 \pm 1.3 \mathrm{a}$ & $0.0 \pm 0.0$ & $1.5 \pm 1.1$ & $6.5 \pm 3.2$ & $34.5 \pm 4.9$ \\
\hline 16 & $23.1 \pm 3.7 \mathrm{~b}$ & $100.0 \pm 0.0 \mathrm{c}$ & $2.3 \pm 1.6 \mathrm{a}$ & $2.7 \pm 1.8 \mathrm{a}$ & $2.2 \pm 2.0$ & $2.6 \pm 1.7$ & $5.3 \pm 3.3$ & $22.2 \pm 5.0$ \\
\hline 40 & $78.2 \pm 4.7 \mathrm{c}$ & $100.0 \pm 0.0 \mathrm{c}$ & $9.5 \pm 3.1 \mathrm{~b}$ & $50.5 \pm 3.5 b$ & $2.7 \pm 1.3$ & $4.4 \pm 2.3$ & $12.0 \pm 5.7$ & $36.9 \pm 8.9$ \\
\hline
\end{tabular}

ticulatus, the numbers of adults and nymphs were recorded separately.

Data Analysis. The immediate and delayed mortality counts were analyzed separately for each species by using the MANOVA Fit Repeated Measures Procedure of JMP software (Sall et al. 2001). For progeny production, a two-way analysis of variance (ANOVA) was used, with number of progeny as the response variable, and exposure and commodity as main effects. For T. castaneum and L. reticulatus, the numbers of different life stages were analyzed separately. Means were separated by the Tukey-Kramer honestly significant difference (HSD) test at 0.05 (Sokal and Rohlf 1994).

\section{Results}

Immediate Mortality. For all species, main effects immediate mortality and commodity were significant, with the exception of commodity for R. dominica (Table 1). For this species, mortality after $16 \mathrm{~h}$ on wheat was significantly increased in comparison with shorter intervals and the control and reached $78 \%$ after $40 \mathrm{~h}$ of exposure (Table 2). Similar mortality levels also were noted on treated maize, on which $72 \%$ of the adults were dead after $40 \mathrm{~h}$ of exposure (Table 3$)$. Immediate mortality of S. oryzae was low $(<10 \%)$ on treated wheat (Table 2 ). In contrast, immediate mortality reached $30 \%$ at the $40-\mathrm{h}$ exposure interval on maize (Table 3). Immediate mortality of T. castaneum was $<4 \%$, regardless of the exposure interval or commodity (Tables 2 and 3). Immediate mortality of $L$. reticulatus reached $12 \%$ on wheat but did not differ from control mortality (Table 2 ). Immediate mortality of $L$. reticulatus on maize reached $29 \%$ after 40 -h of exposure (Table 3).
Delayed Mortality. For all species, delayed mortality was significant, with the exception of T. castaneum (Table 1). Delayed mortality of $R$. dominica reached $100 \%$ at exposures of $4 \mathrm{~h}$ or higher, and at the 2-h exposure was 87 and $93 \%$ for wheat and maize, respectively (Tables 2 and 3). Delayed mortality for $S$. oryzae on wheat was significantly higher than the controls only at the 40 -h exposure, where $50 \%$ of the adults were dead (Table 2). Similarly, on maize, mortality at the 40 -h of exposure was $46 \%$ (Table 3 ). In contrast, T. castaneum delayed mortality was negligible in both commodities (Tables 2 and 3). Finally, $L$. reticulatus delayed mortality reached 37 and $56 \%$ for adults that were previously exposed for $40 \mathrm{~h}$ on wheat and maize, respectively, but delayed mortality in treated wheat did not differ from that in the control.

Progeny Production. Main effect exposure, with the exception of $S$. oryzae, and commodity, with the exception of $T$. castaneum pupae, were significant (Table $4)$. For $R$. dominica, progeny production was significantly reduced in the treated wheat in comparison with the control, and no adult emergence was noted when parental adults had been exposed for 16 or $40 \mathrm{~h}$ (Table 5). Progeny production generally was lower on maize than wheat, and no progeny production was recorded at exposures of $8 \mathrm{~h}$ or higher. In contrast, progeny production of $S$. oryzae on wheat was high and exceeded 213 adults per vial; no significant differences were noted among treatments or between treatments and the control (Table 5). On maize, the number of adults emerged was reduced in comparison with wheat. Progeny production decreased with the increase of the parental exposure interval, but it was still relatively high $(\approx 18$ adults per vial) even after the 40-h interval (Table 6). Significant differences with no

Table 3. Mean immediate and delayed mortality $(\% \pm \mathrm{SE})$ for the species tested after exposure for $0,2,4,8,16$, and $40 \mathrm{~h}$ in spinosad-treated maize (within each column, means followed by the same letter are not significantly different; where no letters exist, no significant differences were noted; HSD test at 0.05 )

\begin{tabular}{|c|c|c|c|c|c|c|c|c|}
\hline \multirow{3}{*}{ Exposure $(\mathrm{h})$} & \multicolumn{8}{|c|}{ Species/mortality } \\
\hline & \multicolumn{2}{|c|}{ R. dominica } & \multicolumn{2}{|c|}{ S. oryzae } & \multicolumn{2}{|c|}{ T. castaneum } & \multicolumn{2}{|c|}{ L. reticulatus } \\
\hline & Immediate & Delayed & Immediate & Delayed & Immediate & Delayed & Immediate & Delayed \\
\hline 0 & $0.0 \pm 0.0 \mathrm{a}$ & $1.6 \pm 0.6 \mathrm{a}$ & $0.0 \pm 0.0 \mathrm{a}$ & $0.0 \pm 0.0 \mathrm{a}$ & $0.0 \pm 0.0$ & $0.0 \pm 0.0 \mathrm{a}$ & $0.0 \pm 0.0 \mathrm{a}$ & $19.9 \pm 5.6 \mathrm{a}$ \\
\hline 2 & $1.0 \pm 1.0 \mathrm{a}$ & $92.9 \pm 3.8 b$ & $1.1 \pm 0.7 \mathrm{a}$ & $6.6 \pm 5.0 \mathrm{ab}$ & $0.0 \pm 0.0$ & $1.3 \pm 1.0 \mathrm{a}$ & $15.5 \pm 5.7 \mathrm{~b}$ & $36.7 \pm 7.5 \mathrm{ab}$ \\
\hline 4 & $0.0 \pm 0.0 \mathrm{a}$ & $100.0 \pm 0.0 \mathrm{c}$ & $1.0 \pm 0.7 \mathrm{a}$ & $2.4 \pm 1.7 \mathrm{a}$ & $0.0 \pm 0.0$ & $6.5 \pm 1.8 \mathrm{ab}$ & $17.2 \pm 6.7 \mathrm{~b}$ & $38.3 \pm 9.1 \mathrm{ab}$ \\
\hline 8 & $3.7 \pm 1.3 \mathrm{a}$ & $100.0 \pm 0.0 \mathrm{c}$ & $3.3 \pm 2.0 \mathrm{a}$ & $8.2 \pm 4.4 \mathrm{ab}$ & $1.0 \pm 1.0$ & $2.7 \pm 2.3 \mathrm{ab}$ & $13.3 \pm 4.5 b$ & $39.5 \pm 5.8 \mathrm{ab}$ \\
\hline 16 & $20.7 \pm 3.2 b$ & $100.0 \pm 0.0 \mathrm{c}$ & $16.0 \pm 7.8 \mathrm{~b}$ & $19.6 \pm 8.6 b$ & $1.0 \pm 1.0$ & $3.8 \pm 2.9$ & $16.6 \pm 8.3 b$ & $39.0 \pm 7.3 \mathrm{ab}$ \\
\hline 40 & $72.2 \pm 8.2 \mathrm{c}$ & $100.0 \pm 0.0 \mathrm{c}$ & $29.5 \pm 9.1 b$ & $46.0 \pm 9.1 c$ & $3.3 \pm 2.3$ & $9.2 \pm 4.5 \mathrm{~b}$ & $29.1 \pm 7.7 \mathrm{~b}$ & $55.7 \pm 6.6 \mathrm{~b}$ \\
\hline
\end{tabular}


Table 4. ANOVA parameters for progeny production of the species tested (in all cases, total df $=59$ )

\begin{tabular}{|c|c|c|c|c|c|c|c|c|c|c|c|c|c|c|c|}
\hline \multirow[t]{2}{*}{ Source } & \multirow[t]{2}{*}{$\mathrm{df}$} & \multicolumn{2}{|c|}{$\begin{array}{l}\text { R. dominica } \\
\text { adults }\end{array}$} & \multicolumn{2}{|c|}{$\begin{array}{l}\text { S. oryzae } \\
\text { adults }\end{array}$} & \multicolumn{2}{|c|}{$\begin{array}{l}\text { T. castaneum } \\
\text { adults }\end{array}$} & \multicolumn{2}{|c|}{$\begin{array}{c}T . \\
\text { castaneum } \\
\text { pupae }\end{array}$} & \multicolumn{2}{|c|}{$\begin{array}{l}\text { T. castaneum } \\
\text { larvae }\end{array}$} & \multicolumn{2}{|c|}{$\begin{array}{l}\text { L. reticulatus } \\
\text { adults }\end{array}$} & \multicolumn{2}{|c|}{$\begin{array}{c}L . \\
\text { reticulatus } \\
\text { nymphs }\end{array}$} \\
\hline & & $F$ & $P$ & $F$ & $P$ & $F$ & $P$ & $F$ & $P$ & $F$ & $P$ & $F$ & $P$ & $F$ & $P$ \\
\hline Exposure & 5 & 41.7 & $<0.01$ & 1.6 & 0.18 & 4.5 & $<0.01$ & 1.3 & 0.27 & 2.7 & 0.03 & 3.0 & 0.02 & 3.0 & 0.02 \\
\hline Commodity & 1 & 30.0 & $<0.01$ & 275.2 & $<0.01$ & 51.4 & $<0.01$ & 3.0 & 0.09 & 13.0 & $<0.01$ & 281.7 & $<0.01$ & 4.6 & 0.04 \\
\hline $\begin{array}{l}\text { Exposure } \times \\
\text { commodity }\end{array}$ & 5 & 25.4 & $<0.01$ & 1.0 & 0.41 & 2.8 & 0.03 & 1.6 & 0.17 & 2.1 & 0.09 & 2.8 & 0.03 & 3.3 & 0.01 \\
\hline
\end{tabular}

obvious pattern observed were noted for adult progeny among treatments for T. castaneum on wheat, but no significant differences were noted for pupae or larvae (Table 5). No significant differences were noted for any of the life stages on maize (Table 6). Number of adult progeny was significantly reduced only for L reticulatus on wheat at the 40-h parental exposure in comparison with the control, but no differences were found for nymphs (Table 5). There were few adult progeny on maize, and no significant differences were noted. The number of nymphs was significantly lower than the control in most of the exposure periods tested (Table 6).

\section{Discussion}

The results of the current study indicate that short exposure intervals to spinosad-treated grains, at the exposure range examined here, can kill the exposed adults and affect their reproduction rates before death, but these effects vary according to the species, exposure interval, and commodity. For another group of protectants, pyrethroids, Athanassiou et al. (2004b) reported that despite the fact that relatively high parental survival of Tribolium confusum Jacquelin du Val (Coleoptera: Tenebrionidae) occurred after $7 \mathrm{~d}$ of exposure on wheat treated with beta-cyfluthrin, no progeny were produced when the surviving adults were transferred to untreated wheat flour. However, parental individuals exposed on wheat treated with deltamethrin or alphacypermethrin produced progeny. We found that $R$. dominica was by far the most susceptible species to spinosad-treated commodities. This is in agreement with numerous previous studies on wheat (Fang et al. 2002a,b; Fang and Subramanyam 2003; Huang et al. 2004; Nayak et al. 2005; Athanassiou et al. 2008a,b; Getchell and Subramanyam 2008) or maize (Maier et al. 2006, Athanassiou et al. 2008a, Getchell and Subramanyam 2008) or other commodities, such as barley; rice, Oryza sativa L.; or sorghum (Sorghum spp.) (Getchell 2006, Athanassiou et al. 2008a, Getchell and Subramanyam 2008). For example, Nayak et al. (2005) found that spinosad was very effective against OP-resistant $R$. dominica populations. Getchell and Subramanyam (2008) examined the immediate mortality of $R$. dominica and S. oryzae adults on wheat, maize, and sorghum treated with spinosad at various exposure intervals, and delayed mortality $24 \mathrm{~h}$ after the removal of the exposed adults from the treated grains. In that work, $R$. dominica was always more susceptible than $S$. oryzae, but delayed mortality did not exceed $58 \%$. In the present work, all $R$. dominica adults that were previously exposed to spinosad for intervals longer than $2 \mathrm{~h}$ were dead $7 \mathrm{~d}$ later. Hence, by combining the results from both studies, we can conclude that the postexposure time is one of the crucial factors that determine delayed mortality, and that $24 \mathrm{~h}$ may not be a sufficient interval to reflect the postexposure poisoning effect of spinosad. In addition, our results indicate that $R$. dominica parental mortality is directly related to reduced progeny production. This trend was more evident on maize, which can be considered as an apparent consequence of the lower suitability for development on this commodity in comparison with wheat.

On wheat, short exposures affected delayed mortality of S. oryzae adults, but only at the 40-h exposure interval. However, parental mortality did not result in a concomitant reduction in progeny production, and the number of weevils that emerged was as high as in the control. Consequently, progeny production was not analogous to parental mortality, suggesting that the speed of kill is the main factor that determines level of oviposition. Thus, even if delayed mortality was as high as $50 \%$, overall progeny production remained unaffected. However, the speed of kill on

Table 5. Mean progeny production (individuals/vial) for the species tested after exposure of the parental adults for $0,2,4,8,16$, and $40 \mathrm{~h}$ in spinosad-treated wheat (within each column, means followed by the same letter are not significantly different; where no letters exist, no significant differences were noted; HSD test at 0.05 )

\begin{tabular}{|c|c|c|c|c|c|c|c|}
\hline \multirow[b]{2}{*}{ Exposure (h) } & \multicolumn{7}{|c|}{ Species/progeny } \\
\hline & $\begin{array}{l}\text { R. dominica } \\
\text { adults }\end{array}$ & $\begin{array}{l}\text { S. oryzae } \\
\text { adults }\end{array}$ & $\begin{array}{l}\text { T. castaneum } \\
\text { adults }\end{array}$ & $\begin{array}{l}\text { T. castaneum } \\
\text { pupae }\end{array}$ & $\begin{array}{c}\text { T. castaneum } \\
\text { larvae }\end{array}$ & $\begin{array}{l}\text { L. reticulatus } \\
\text { adults }\end{array}$ & $\begin{array}{l}\text { L. reticulatus } \\
\text { nymphs }\end{array}$ \\
\hline 0 & $256.4 \pm 42.4 \mathrm{a}$ & $282.8 \pm 34.2$ & $13.8 \pm 5.1 \mathrm{a}$ & $15.4 \pm 5.1$ & $15.6 \pm 8.2$ & $96.6 \pm 4.4 \mathrm{a}$ & $13.6 \pm 2.9$ \\
\hline 2 & $15.0 \pm 9.9 b$ & $232.0 \pm 21.9$ & $22.8 \pm 2.5 \mathrm{a}$ & $11.2 \pm 1.3$ & $9.6 \pm 4.6$ & $85.6 \pm 6.0 \mathrm{ab}$ & $12.0 \pm 5.5$ \\
\hline 4 & $2.2 \pm 1.7 \mathrm{~b}$ & $228.0 \pm 14.9$ & $58.4 \pm 12.9 \mathrm{~b}$ & $6.6 \pm 1.4$ & $10.2 \pm 6.1$ & $78.4 \pm 17.1 \mathrm{ab}$ & $12.4 \pm 3.2$ \\
\hline 8 & $0.2 \pm 0.2 b$ & $214.6 \pm 41.2$ & $29.4 \pm 9.3 \mathrm{ab}$ & $14.6 \pm 2.8$ & $7.4 \pm 1.7$ & $68.8 \pm 8.4 \mathrm{ab}$ & $22.4 \pm 6.1$ \\
\hline 16 & $0.0 \pm 0.0 \mathrm{~b}$ & $289.2 \pm 39.0$ & $18.2 \pm 7.2 \mathrm{a}$ & $3.0 \pm 0.8$ & $7.0 \pm 2.7$ & $94.4 \pm 15.9 \mathrm{a}$ & $12.0 \pm 3.0$ \\
\hline 40 & $0.0 \pm 0.0 \mathrm{~b}$ & $213.2 \pm 20.8$ & $24.6 \pm 7.1 \mathrm{ab}$ & $12.2 \pm 5.9$ & $22.6 \pm 7.1$ & $46.6 \pm 6.0 \mathrm{~b}$ & $4.4 \pm 1.2$ \\
\hline
\end{tabular}


Table 6. Mean progeny production (individuals/vial) for the species tested after exposure of the parental adults for $0,2,4,8,16$, and $40 \mathrm{~h}$ in spinosad-treated maize (within each column, means followed by the same letter are not significantly different; where no letters exist, no significant differences were noted; HSD test at 0.05)

\begin{tabular}{|c|c|c|c|c|c|c|c|}
\hline \multirow[b]{2}{*}{ Exposure (h) } & \multicolumn{7}{|c|}{ Species/progeny } \\
\hline & $\begin{array}{l}\text { R. dominica } \\
\text { adults }\end{array}$ & $\begin{array}{l}\text { S. oryzae } \\
\text { adults }\end{array}$ & $\begin{array}{l}\text { T. castaneum } \\
\text { adults }\end{array}$ & $\begin{array}{c}\text { T. castaneum } \\
\text { pupae }\end{array}$ & $\begin{array}{l}\text { T. castaneum } \\
\text { larvae }\end{array}$ & $\begin{array}{l}\text { L. reticulatus } \\
\text { adults }\end{array}$ & L. reticulatus \\
\hline 0 & $31.6 \pm 6.3 \mathrm{a}$ & $48.4 \pm 5.2 \mathrm{a}$ & $1.4 \pm 0.9$ & $3.2 \pm 1.6$ & $20.6 \pm 5.3$ & $3.0 \pm 0.5$ & $19.2 \pm 2.2 \mathrm{a}$ \\
\hline 2 & $0.6 \pm 0.4 b$ & $31.4 \pm 7.6 \mathrm{ab}$ & $3.6 \pm 2.5$ & $5.6 \pm 3.2$ & $35.0 \pm 22.4$ & $5.8 \pm 2.4$ & $11.4 \pm 2.3 \mathrm{ab}$ \\
\hline 4 & $0.2 \pm 0.2 \mathrm{~b}$ & $36.0 \pm 6.3 \mathrm{ab}$ & $6.4 \pm 3.2$ & $13.2 \pm 5.7$ & $89.8 \pm 31.2$ & $2.2 \pm 1.2$ & $3.8 \pm 2.0 \mathrm{a}$ \\
\hline 8 & $0.0 \pm 0.0 \mathrm{~b}$ & $38.2 \pm 6.5 \mathrm{ab}$ & $6.0 \pm 4.3$ & $10.0 \pm 5.5$ & $20.8 \pm 5.2$ & $5.0 \pm 2.9$ & $3.4 \pm 1.2 \mathrm{~b}$ \\
\hline 16 & $0.0 \pm 0.0 \mathrm{~b}$ & $27.8 \pm 3.8 b$ & $0.8 \pm 0.4$ & $3.8 \pm 1.4$ & $16.0 \pm 6.4$ & $1.4 \pm 0.5$ & $9.6 \pm 4.7 \mathrm{ab}$ \\
\hline 40 & $0.0 \pm 0.0 \mathrm{~b}$ & $17.6 \pm 8.6 \mathrm{~b}$ & $1.6 \pm 0.8$ & $5.6 \pm 2.8$ & $61.8 \pm 22.3$ & $1.0 \pm 0.8$ & $4.4 \pm 1.5 b$ \\
\hline
\end{tabular}

maize was higher than on wheat, given that mortality was significantly higher than the controls even after $16 \mathrm{~h}$ of exposure. This was directly reflected in a reduction in progeny production; still, as described above, this can be considered as an indirect result of different developmental rates of $S$. oryzae on the two commodities (Chintzoglou et al. 2008a).

T. castaneum was practically unaffected by short exposures to treated wheat and maize. Toews and Subramanyam (2003) found that T. confusum and $T$. castaneum were the least susceptible among eight beetle species exposed to spinosad-treated surfaces. Similar studies have been also published for both species with liquid spinosad (Fang et al. 2002a, Nayak et al. 2005, Athanassiou et al. 2008b) and dry spinosad (Getchell 2006, Chintzoglou et al. 2008b, Getchell and Subramanyam 2008), indicating also that Tribolium species are less susceptible than $R$. dominica or S. oryzae. Thus, Tribolium species can be classified among the most tolerant stored-grain insect species to spinosad.

There are no published data on the effects of short exposures to spinosad in stored-product psocids. Nayak et al. (2005) evaluated spinosad against four psocid species, Liposcelis bostrychophila Badonnel, Liposcelis decolor (Pearman), Liposcelis entomophila (Enderlein), and Liposcelis paeta Pearman (Psocoptera: Liposcelididae) on wheat. They reported that $1 \mathrm{ppm}$ spinosad was effective against L. entomophila, but not the other three species. However, there are no data for L. reticulatus. Our results suggest that short exposures of L. reticulatus adults on treated wheat had no effect on mortality, but, paradoxically, progeny production was significantly affected. In contrast, delayed mortality was increased with increased exposure on treated maize, but there was no effect on progeny production. For this species, progeny production on maize was lower than that on wheat. Opit and Throne (2008) found that wheat was more suitable than maize for the development and population growth of $L$. reticulatus.

Chintzoglou et al. (2008a,b) found that there was accelerated degradation of dry spinosad on maize within $14 \mathrm{~d}$ of application, but not on wheat, and dry spinosad was generally more effective on wheat than on maize against $S$. oryzae and T. confusum. Fang et al. (2002a) reported that liquid spinosad was not equally effective among different classes of wheat, but there was no correlation of efficacy with some of the basic physical or chemical parameters of the grains tested.
It is not clear whether any differences in spinosad efficacy among commodities can be attributed to the chemical and physical characteristics of the commodities. However, Getchell and Subramanyam (2008) indicate that although both dry and liquid spinosad performed differently among wheat, maize, and sorghum, there were no consistent differences among commodities. In our study, despite the fact that differences between wheat and maize occurred, these seem to be mainly due to differences in development and reproduction parameters among commodities.

In summary, among the four species tested here, short exposures are effective only against $R$. dominica. This species was highly affected even by a short contact with spinosad, such as $2-4 \mathrm{~h}$. Short exposures may play a role in cases of partially-treated substrates, such as the "surface" treatment, on which only the upper layer of the grain bulk is treated. Under this scenario, it is expected that even if $R$. dominica adults pass though the upper, treated layer, death will occur rapidly in deeper, untreated, parts of the bulk, resulting in reduced or no progeny. In contrast, short exposures do not prevent grains from further infestation by the other three species, and longer exposure durations should be evaluated. Additional experimentation is needed to evaluate the role of and any potential utility of short exposures in field tests, e.g., partially treated grain bulks.

\section{Acknowledgments}

We thank Ann Redmon and Ngunza Kisangani for technical support. We thank Dow Agrosciences for providing the spinosad sample. We thank Manoj Nayak for comments on an earlier version of this work.

\section{References Cited}

Arthur, F. H. 1992. Efficacy of chlorpyriphos-methyl for control of maize weevils (Coleoptera: Curculionidae) and red flour beetles (Tenebrionidae) in mixtures of treated and untreated corn. J. Econ. Entomol. 85: 554-560.

Arthur, F. H. 1996. Grain protectants: current status and prospects for the future. J. Stored Prod. Res. 32: 293-302.

Arthur, F. H. 1998a. Effects of food source on red flour beetle (Coleoptera: Tenebrionidae) survival after exposure on concrete treated with cyfluthrin. J. Econ. Entomol. 91: 773-778.

Arthur, F. H. 1998b. Residual studies with cyfluthrin wettable powder: toxicity toward red flour beetles (Co- 
leoptera: Tenebriondae) exposed for short intervals on treated concrete. J. Econ. Entomol. 91: 309-319.

Arthur, F. H., and J. E. Throne. 2003. Efficacy of diatomaceous earth to control internal infestations of rice weevil and maize weevil (Coleoptera: Curculionidae). J. Econ. Entomol. 96: 510-518.

Athanassiou, C. G., N. G. Kavallieratos, F. C. Tsaganou, B. J. Vayias, C. B. Dimizas, and C. T. Buchelos. 2003. Effect of grain type on the insecticidal efficacy of SilicoSec against Sitophilus oryzae (L.) (Coleoptera: Curculionidae). Crop Prot. 22: 1141-1147.

Athanassiou, C. G., N. G. Kavallieratos, and N. S. Andris. 2004a. Insecticidal effect of three diatomaceous earth formulations against adults of Sitophilus oryzae (Coleoptera: Curculionidae) and Tribolium confusum (Coleoptera: Tenebrionidae) on oat, rye and triticale. J. Econ. Entomol. 97: 2160-2167.

Athanassiou, C. G., N. G. Kavallieratos, B. J. Vayias, C. B. Dimizas, A. S. Papagregoriou, and C. Th. Buchelos. 2004b. Residual toxicity of beta cyfluthrin, alpha cypermethrin and deltamethrin against Tribolium confusum Jacquelin du Val (Coleoptera: Tenebrionidae) on stored wheat. Appl. Entomol. Zool. 39: 195-202.

Athanassiou, C. G., N. G. Kavallieratos, G. J. Chintzoglou, G. G. Peteinatos, M. C. Boukouvala, S. S. Petrou, and E. C. Panoussakis. 2008a. Effect of temperature and humidity on insecticidal efficacy of spinosad dust against Sitophilus oryzae (Coleoptera: Curculionidae) and Rhyzopertha dominica (Coleoptera: Bostrychidae). J. Econ. Entomol. 101: 976-981.

Athanassiou, C. G., N. G. Kavallieratos, A. E. Yiatilis, B. J. Vayias, C. S. Mavrotas, and Z. Tomanovic. 2008b. Influence of temperature and humidity on the efficacy of spinosad against four stored-grain beetle species. J. Insect Sci. 60: 1-9.

Chintzoglou, G. J., C. G. Athanassiou, A. A. Markoglou, and N. G. Kavallieratos. 2008a. Influence of commodity on the effect of spinosad dust against Rhyzopertha dominica (F.) (Coleoptera: Bostrychidae) and Sitophilus oryzae (L.) (Coleoptera: Curculionidae). Int. J. Pest Manag. 54: 277-285.

Chintzoglou, G. J., C. G. Athanassiou, and F. H. Arthur. 2008b. Insecticidal effect of spinosad dust, in combination with diatomaceous earth, against two stored-grain beetle species. J. Stored Prod. Res. 44: 347-353.

Daglish, G. J., and M. K. Nayak. 2006. Long-term persistence and efficacy of spinosad against Rhyzopertha dominica (Coleoptera: Bostrychidae) in wheat. Pest Manag. Sci. 62: 148-152.

Daglish, G. J., M. B. Head, and P. B. Hughes. 2008. Field evaluation of spinosad as a grain protectant for stored wheat in Australia: efficacy against Rhyzopertha dominica (F.) and fate of residues in whole wheat and milling fractions. Aust. J. Entomol. 47: 70-74.

Fang, L., and Bh. Subramanyam. 2003. Activity of spinosad against adults of Rhyzopertha dominica (F.) (Coleoptera: Bostrychidae) is not affected by wheat temperature and moisture. J. Kans. Entomol. Soc. 75: 529-532.

Fang, L., Bh. Subramanyam, and F. H. Arthur. 2002a. Effectiveness of spinosad on four classes of wheat against five stored product insects. J. Econ. Entomol. 95: 640 - 650.

Fang, L., Bh. Subramanyam, and S. Dolder. 2002b. Persistence and efficacy of spinosad residues in farm stored wheat. J. Econ. Entomol. 95: 1102-1109.
Getchell, A. I. 2006. Efficacy of two spinosad formulations on various commodities against stored product insects. M.S. thesis. Kansas State University, Manhattan.

Getchell, A. I., and Bh. Subramanyam. 2008. Immediate and delayed mortality of Rhyzopertha dominica and Sitophilus oryzae adults exposed to spinosad-treated commodities. J. Econ. Entomol. 101: 1022-1027.

Huang, F., and Bh. Subramanyam. 2004. Responses of Corcyra cephalonica (Stainton) to pirimiphos-methyl, spinosad, and combinations of pirimiphos-methyl and synergized pyrethrins. Pest Manag. Sci. 60: 191-198.

Huang, F., Bh. Subramanyam, and M. D. Toews. 2004. Susceptibility of laboratory and field strains of four storedproduct insects to spinosad. J. Econ. Entomol. 97: 2154-2159.

Maier, D. E., K. E. Ileleji, and D. Szabela. 2006. Efficacy of spinosad for insect management in stored maize, pp. 789 796. In I. Lorini, B. Bacaltchuk, H. Beckel, D. Deckers, E Sundfeld, J. P. dos Santos, J. D. Biagi, J. C. Celaro, L. R. D’ A. Faroni, L. de O. F. Bortolini, M. R. Sartori, M. C. Elias, R.N.C. Guedes, R. G. da Fonseca, and V. M. Scussel [eds.], Proceedings of the 9th International Working Conference on Stored-Product Protection, 15-18 October 2006, Campinas, Sao Paulo, Brazil. Brazilian Post Harvest Association, Campinas, Brazil.

Mockford, E. L. 1993. North American Psocoptera. The Sandhill Crane Press, Inc., Gainesville, FL.

Nayak, M. K., G. J. Daglish, and V. S. Byrne. 2005. Effectiveness of spinosad as a grain protectant against resistant beetle and psocid pests of stored grain in Australia. J. Stored Prod. Res. 41: 455-467.

Opit, G. P., and J. E. Throne. 2008. Effects of diet on population growth of psocids Lepinotus reticulatus and $\mathrm{Li}$ poscelis entomophila. J. Econ. Entomol. 101: 616-622.

Sall, J., A. Lehman, and L. Creighton. 2001. JMP Start Statistics. A guide to statistics and data analysis using JMP and JMP IN software. Duxbury Press, Belmont, CA.

Sokal, R. R., and F. J. Rohlf. 1994. Biometry, 3rd ed. Freeman, New York.

Subramanyam, Bh. 2006. Performance of spinosad as a stored grain protectant, pp. 250-257. In I. Lorini, B. Bacaltchuk, H. Beckel, D. Deckers, E. Sundfeld, J. P. dos Santos, J. D. Biagi, J. C. Celaro, L. R. D’ A. Faroni, L. de O. F. Bortolini, M. R. Sartori, M. C. Elias, R.N.C. Guedes, R. G. da Fonseca, and V. M. Scussel [eds.], Proceedings of the 9th International Working Conference on StoredProduct Protection, 15-18 October 2006, Campinas, Sao Paulo, Brazil. Brazilian Post Harvest Association, Campinas, Brazil.

Subramanyam, Bh., M. D. Toews, K. E. Ilelejic, D. E. Maier, G. D. Thompson, and T. J. Pitts. 2007. Evaluation of spinosad as a grain protectant on three Kansas farms. Crop Prot. 26: 1021-1030.

Toews, M. D., and Bh. Subramanyam. 2003. Contribution of contact toxicity and wheat condition to mortality of stored-product insects exposed to spinosad. Pest Manag. Sci. 59: 538-544.

Vardeman, E. A., F. H. Arthur, J. R. Nechols, and J. F. Campbell. 2007. Efficacy of surface applications with diatomaceous earth to control Rhyzopertha dominica (F.) (Coleoptera: Bostrychidae) in stored wheat. J. Stored Prod. Res. 43: 335-341.

Received 17 April 2009; accepted 18 August 2009. 